\title{
Mothers of children with an orofacial cleft: Satisfaction with motherhood and experience of stress
}

\author{
Annemieke Bos ${ }^{1 *}$, Charlotte Prahl ${ }^{1}$ and Paula S. Sterkenburg ${ }^{2,3}$ \\ ${ }^{1}$ Department of Orthodontics, Academic Centre of Dentistry Amsterdam, Amsterdam, The Netherlands \\ ${ }^{2}$ Vrije Universiteit Amsterdam, Faculty of Behavioural and Movement Sciences, Clinical Child and Family Studies Amsterdam Public Health research institute, Van der \\ Boechorststraat 1, 1081 BT Amsterdam, The Netherlands \\ ${ }^{3}$ Bartiméus, P.O. Box 87, 3940 AB, Doorn, The Netherlands
}

\begin{abstract}
Objective: To investigate and compare stress and satisfaction with motherhood of mothers of children with versus without an orofacial cleft. Setting: Cleft palate center and a child day care in Amsterdam, The Netherlands.

Participants: Seventy six mothers with children aged 0-4 years with clefts were included. The children were treated at the academic cleft palate center in Amsterdam, The Netherlands. Fifty two mothers with children of similar age but with no orofacial cleft attending child day care comprised the comparator group.

Main Outcome measures: Mean satisfaction with motherhood and scores for the stress were obtained from 'Motherhood Satisfaction' and 'NOSI-k' (Nijmeegse Ouderlijke Stress Index short form) questionnaires.

Results: No significant difference was observed between the two groups on subscales or the overall 'Motherhood Satisfaction' and 'NOSI-k' questionnaires . Only an item regarding comfort consulting family/friends about concerns differed significantly. Regression analysis showed that the 'Competence' for the mothers of children with cleft palate and 'Behavior Child' in the child day care group were significant predictors of the 'Satisfaction with Motherhood' grade.
\end{abstract}

Conclusions: Mothers of children with clefts did not differ substantively in their satisfaction with motherhood and they experienced the same stress level as mothers of children without cleft palates.

\section{Introduction}

Raising a child with a congenital craniofacial anomaly like a cleft lip and/or an alveolus cleft and/or a palate cleft (orofacial cleft) brings many challenges [1-3]. Parents of a child with an orofacial cleft must quickly learn to handle the new situation after the shock and disappointment of hearing of their child's birth defect [4-7].

The period immediately after birth is often a difficult time for parents of children with an orofacial cleft [8-13]. This particular period may bring forth many different feelings [14-16]. Questions may arise about what went wrong during pregnancy, the uncertainty of having a future child with a congenital malformation, and uncertainty about the future and the quality of life of their child $[17,18]$. All these feelings can potentially lead parents to experience stress $[5,14,18,19]$.

The question as to whether there are higher levels of stress in parents with children who have a craniofacial anomaly than in parents of children without a craniofacial anomaly, especially mothers, is still controversial [20-22]. The degree of stress appears to be determined by how parents deal with the fact that their child has a disability rather than the presence of the disability itself [22,23].

Parental stress may be a predictor of children's later psychosocial adjustment, and may have a negative effect on the development of the parent-child relationship $[9,10,16,20,24]$. Parents who experience significant stress in the early years of parenthood may be more likely to have children who later may behave in a problematic manner and have a lower self-concept, higher aggression levels, and more negative problem solving strategies $[1,11,16,18,24]$. Therefore, it is important to ensure that parents experience as little stress as possible, since it may increase the possibility that a child becomes more secure and balanced in later life.

In a previous study in the Netherlands, the 'Motherhood Satisfaction' questionnaire was used to measure the satisfaction of motherhood in mothers of children with an unilateral cleft lip and a cleft palate (UCLP), with and without the use of an orthodontic plate [7]. The overall result from this study showed that an orthodontic plate in children with UCLP during the first year of life had no influence on their mothers' satisfaction with motherhood compared with mothers of children without an orthodontic plate [7]. There is a lot of pressure on mothers of a child with a cleft because of hospital visits, feeding difficulties, a negative social response from the environment, and less interplay between the mother and child [12,25]. Do mothers of

Correspondence to: A Bos, Assistant professor, Department of Orthodontics, Academic Centre of Dentistry Amsterdam, Gustav Mahlerlaan 3004, 1081 LA Amsterdam, The Netherlands, Tel: +31-20-59-80-468; E-mail: a.bos@acta.nl

Key words: orofacial cleft, motherhood satisfaction, parental stress

Received: August 23, 2017; Accepted: September 06, 2017; Published: September 09, 2017 
children with an orofacial cleft differ in satisfaction with motherhood from mothers of a child without an orofacial cleft?

The aim of this study was to investigate the stress level and satisfaction with motherhood of mothers of a child with an orofacial cleft versus those with a child without an orofacial cleft. Possible differences between these two groups of mothers were explored.

\section{Methods}

\section{Participants}

The first group of mothers had children who were treated by the cleft team at the Academic Centre of Dentistry Amsterdam. This team consisted of staff from the departments of plastic surgery; medical social work; orthodontics; ear, nose, and throat (ENT); speech therapy; pediatrics; clinical genetics; oral surgery; pediatric dentistry; and maxillofacial prosthetics. The patient inclusion criteria were: a child with a cleft lip and/or an alveolus cleft and/or a palate cleft, with no other congenital malformations besides the orofacial cleft, and aged 0-4 years. This group of mothers will be referred to as the patient group.

The second group of mothers had children who were brought to a paid child day care during the day. The child day care was located in the same neighborhood as the Academic Centre of Dentistry Amsterdam (a distance of a proximally 3 yards). The patient inclusion criteria for the child day care group were children with no cleft lip and/ or an alveolus cleft and/or a palate cleft, aged 0-4 years, and with no congenital malformations. This group of mothers will be referred to as the child day care group.

The patient group comprised 76 mothers with children ( 45 boys, 31 girls) who had an orofacial cleft. The mean age of the children was 34.6 months (standard deviation $[\mathrm{SD}] \pm 15.71$ ). The mean age of the mothers was 33.8 years ( $\mathrm{SD} \pm 4.5$ ). On average, they had 1.92 children $(\mathrm{SD} \pm 1.0)$ each. Twenty six children had an isolated cleft palate; 30 had a combination of a cleft lip, an alveolus cleft, and a cleft palate; 7 children had a combination of a cleft lip and a cleft in the alveolus process; and 13 children had an isolated cleft lip.

The child day care group included 52 mothers of children ( 16 boys, 36 girls) without an orofacial cleft. The mean age of the children was 25.7 months ( $\mathrm{SD} \pm 13.8$ ). The mothers had a mean age of 34.8 years (SD $\pm 4.6)$, and on average had 1.54 children ( $\mathrm{SD} \pm 0.75)$ each.

\section{Procedure}

For the patient group, 131 questionnaires were sent to the home addresses. The addresses were obtained from the patient records of the cleft team at the Academic Centre of Dentistry Amsterdam. The subjects were asked to return the completed questionnaire anonymously in the enclosed return envelope. The questionnaires were sent three times to the mothers in order to increase the response rate. In total, 81 questionnaires were returned, giving a response rate of 61.8 percent. Three envelopes were returned unopened because the relevant parent had moved or was unknown at that address. Two returned questionnaires were unusable because one was completed by the father and one questionnaire was left blank.

For the child day care group, 250 questionnaires were distributed at the child day care. The nursery staff handed out the questionnaires to the parents, with a enclosed return envelop. The mothers of the children who received the questionnaire were asked in a letter to participate in the study and to complete the questionnaire. They were assured of their anonymity. Out of 250 questionnaires, 52 were returned for a response rate of 20.8 percent.

\section{Questionnaires}

The questionnaire contained 47 questions and is composed of two parts. The first part of the questionnaire consisted of 18 items and was based on the 'Motherhood Satisfaction' questionnaire [7]. The questions were derived from experiences gathered from a longitudinal study on mother-child attachments in children with an orofacial cleft $[7,26,27]$. The Motherhood Satisfaction questionnaire was originally divided into 4 domains and contained 42 questions. Two of the four domains of the Motherhood Satisfaction Questionnaire were not included in this study because the questions on these two domains do not relate to children aged 0-4 years. The first included domain contains questions concerning feelings of the mother towards the behavior of the baby (10 items); for example 'I am happy with the way my child sleeps' and 'I am happy with the way my child eats and drinks'. The second included domain concerned questions about the support from the woman's partner, relatives, acquaintances, and friends (8 items); for example, 'I am pleased with the contribution my partner makes to the care of my child'.

The second part of the questionnaire was based on the 'NOSI-k' and consisted of 25 items. The 'NOSI-k' is an abridged and Dutchedited version of the American Parenting Stress Index [28-30]. The 'NOSI-k' in the present study contained five subscales (Fastidiousness, Behavior child, Competence, Fatigue and Difficulties child). Examples of the questions are 'My child does things that make me feel pretty unhappy', 'It is not always easy to accept my child the way he/she is', 'I often feel that I can't handle the things I do', 'Since I have had children, I am tired more quickly than before', 'My child often requires more attention from me than I can give'.

In order to get more detailed insight into the situations of the mothers in the patient group, four exploratory questions are added to the questionnaire for the patient group. These questions were used to collect specific information on the perception of the malformation and the cleft team; for example; 'I feel supported by information and advice I got from the cleft team about the care and development of my child'. No comparison with these questions could be made with the child day care group.

All items on the questionnaire were answered on a 6-point scale, with the anchor points 1 (totally disagree) to 6 (totally agree). Negatively formulated items on the 'NOSI-k' questionnaire were rescored so that a higher mean score reflects an increased satisfaction with motherhood and a lower perception of stress with motherhood (positive therefore scored with + in Table 1).

The mothers were also asked to grade their satisfaction with motherhood with a number from 1 to 10 , where 1 corresponds for 'not at all satisfied' and 10 corresponds to 'completely satisfied'.

\section{Statistical analysis}

Using SPSS 23.0 for Windows, the data provided by the patient and child day care groups were analyzed. Differences between the two groups regarding age, sex, and number of siblings were analyzed.

The internal consistency of the subscales was examined using Cronbach's alpha. The full questionnaire 'Motherhood Satisfaction and NOSI-k' had a high reliability (Cronbach's $\alpha=0.94$ ). The reliability of the two 'Motherhood Satisfaction' subscales (Cronbach's a 'Doings child' $=0.71$, Cronbach's $\alpha$ 'Support of surrounding area' $=0.75$ ) were satisfactory. The internal consistency of the five 'NOSI-k' subscales 
(Fastidiousness, Behavior child, Competence, Fatigue and Difficulties child) were satisfactory (Cronbach's $\alpha=0.90,0.84,0.84,0.66$ and 0.64 , respectively).

Differences between the two groups were examined with $t$-tests. Mean scores on item, subscale, and total questionnaire levels were computed and compared between the patient and child day care group using independent sample $t$-tests. Subscale scores were determined by summing up the responses on all items of each subscale, and the overall score was calculated by summing up the subscale scores (Table 1). For every individual $t$-test, the critical significance level was adjusted to 0.01 .

Pearson correlation was computed for the patient and child day care group between subscales from the 'NOSI-k', subscales from the 'Motherhood Satisfaction' questionnaire, and the 'Satisfaction with Motherhood' grade (Tables 2 and 3).

Stepwise regression analyses were done for the patient and child day care groups with the five subscales of the 'NOSI- $k$ ' and the two subscales of the 'Motherhood Satisfaction' questionnaires as predictors, and the 'Satisfaction with Motherhood' grade as dependent variable (Table 4). Finally, descriptive statistics of the explorative items in the patient group were computed (Table 5).

\section{Results}

There were no differences in the age of the mothers in the two groups; however, their children differed in age $(t=3.28, \mathrm{p}<0.001)$. Children in the child day care group were younger than those in the patient group. Also, a difference was found between both groups with regard to the sex of the child $\left(\chi^{2}=9.48, p<0.05\right)$ as there were more mothers of boys included in the patient group. Finally, the number of siblings differed between groups $(t=2.31, \mathrm{p}<0.05)$. In the patient group, more children had siblings than in the child day care group.

Both groups scored high on both questionnaires, meaning that mothers of a child with an orofacial cleft were equally satisfied and experienced equivalent stress levels related to motherhood as those in the child day care group.

The mean item scores, SD, and $t$-values are presented in Table 1. For 13 items, mothers of a child with a cleft scored more positively than mothers in the child day care group. This indicates that they experience less stress on these specific items than the child day care group; however, this difference did not reach significance in any of the cases. Subjects in the child day care group scored higher (more satisfied and experienced less stress) on 39 items, only one of which was significant ( $\mathrm{p}<0.01)$; 'If I have problems with my child or if I am concerned about the future, I can talk it through with family or friends'.

Tables 2 and 3 show the results of the correlation analyses between the 'Motherhood Satisfaction' subscales, the 'NOSI-k' subscales, and the 'Satisfaction with Motherhood' grade in the patient group and the child day care group. When comparing both tables, it could be concluded that there was a reverse correlation between perceived stress and satisfaction with motherhood in mothers in both the patient and child day care group. The results in Tables 2 and 3 show that stress and satisfaction with motherhood were indeed related.

The stepwise regression analysis (Table 4) for the patient group showed only one significant predictor, the 'NOSI-k' subscale 'Competence'. This predictor explained $27 \%$ of the variance in the 'Satisfaction with Motherhood' grade in the patient group. The stepwise regression analysis for the child day care group also showed one significant predictor, the 'NOSI-k' subscale 'Behavior Child'.
This predictor explained $20 \%$ of the variance in the 'Satisfaction with Motherhood' grade in the child day care group.

The four exploratory questions relating to the cleft and only asked to the group of mothers of a child with a cleft are shown in Table 5. Mothers of a child with an orofacial cleft scored relatively low on two questions; these were the amount of contact with other parents with a child with a cleft and the feelings of joy during the first weeks after birth.

\section{Discussion}

Parents of a child with an orofacial cleft clearly have challenges to endure. However, there was no evidence that these mothers were not equally satisfied with motherhood or that they experienced a different amount of stress than mothers of children without a cleft. No difference was seen at the subscale level and for the overall 'Motherhood Satisfaction' and 'NOSI-k' questionnaires among the mothers of a child with an orofacial cleft and the child day care group.

The results of this study are in line with previous research by Krueckeberg and Kapp-Simon [20]. They reported no differences on the parenting stress inventory between parents of children with a craniofacial anomaly and parents in a control group. These results agree with the results in the present study. However, the exploratory questions revealed that mothers of a child with an orofacial disorder liked to have more contact with peers. This corresponded to the conclusion of the only item that differed significantly; mothers of a child with an orofacial cleft felt that they could not talk to family and friends when they had problems with their child or if they were concerned about the future ('Motherhood Satisfaction' questionnaire). These results were consistent with a previous study [8], which showed that mothers of children with craniofacial anomalies were less satisfied with the support they received compared to mothers in a control group. Kramer, et al. [6] stated that the social impact increased when the cleft was identified prior to birth.

The regression analysis revealed that the patient and child day care groups had a different predictor for the 'Satisfaction with Motherhood' grade. In the child day care group, the 'NOSI-k' subscale 'Child behavior' was a significant predictor.

The stepwise regression analysis for the patient group showed that the 'Competence' subscale was a significant predictor of the 'Satisfaction with Motherhood' grade. This means that a mothers' perception of herself as a competent parent predicts how satisfied she is with motherhood. Using the original 'Parent Stress Index', Speltz, et al. [13] also found that the subscale 'Competence' was of interest. These researchers demonstrated that parents of children with a craniofacial disorder experienced more stress than parents of children without a craniofacial abnormality. This significant difference was mainly located in the 'Competence' subscale. In the present study, with the use of the 'NOSI-k', only $27 \%$ of satisfaction with motherhood in mothers of a child with a cleft could be predicted with the 'Competence' subscale. Therefore, it can be stated that other factors like individual psychosocial problems, parenting styles, or child factors are probably also important. Further studies are necessary to identify variables like these, which influence the perception of motherhood and perceived stress in mothers of children with a craniofacial disorder.

This study has several limitations. Most important, the sex, age, and number of siblings differed between the patient and the child day care groups, making it more difficult to interpret the findings of this study. In a future study, mothers of children with a cleft and their children should be matched with mothers in the child day care group. 
Table 1. Item mean scores (M), standard deviations (SD), and $t$-values for differences between mothers with cleft children and the control mothers, direction of differences (Di) between mean item scores.

\begin{tabular}{|c|c|c|c|c|c|c|c|}
\hline \multirow{2}{*}{ Instrument } & \multicolumn{2}{|c|}{ Cleft } & \multicolumn{2}{|c|}{ Control } & \multirow{2}{*}{ t-value } & \multirow{2}{*}{$\mathbf{p}$} & \multirow{2}{*}{ Di } \\
\hline & $\mathbf{M}$ & SD & $\mathbf{M}$ & SD & & & \\
\hline \multicolumn{8}{|l|}{ Satisfaction Motherhood Factor 1; Doings child } \\
\hline 1. I am happy with how my child sleeps & 5.36 & 1.04 & 5.42 & 0.83 & -0.393 & NS & + \\
\hline 2. I am happy with how my child eats and drinks & 5.01 & 1.38 & 5.25 & 1 & -1.131 & NS & + \\
\hline $\begin{array}{l}\text { 3. My child can handle, in my opinion, his/her food good (for example, has } \\
\text { not too much trouble of spitting and intestinal colic) }\end{array}$ & 5.47 & 1.16 & 5.77 & 0.47 & -1.995 & NS & + \\
\hline 4. I know in advance about which time my child likes to eat and sleep & 5.71 & 0.49 & 5.56 & 0.54 & 1.640 & NS & - \\
\hline $\begin{array}{l}\text { 5. I am happy with how my child behaves throughout the day (he/she } \\
\text { whines or cries for example, not too much) }\end{array}$ & 5.39 & 0.97 & 5.42 & 0.57 & -0.19 & NS & + \\
\hline 6. My child can be, in my opinion, well comforted when he/she cries & 5.78 & 0.69 & 5.73 & 0.53 & 0.404 & NS & - \\
\hline 7. I am happy with how my child sleeps when I lay him/her in bed & 5.47 & 0.99 & 5.27 & 0.89 & 1.199 & NS & - \\
\hline $\begin{array}{l}\text { 8. I am happy with how my child behaves as he/she needs to entertain } \\
\text { himself/herself }\end{array}$ & 5.36 & 0.88 & 5.21 & 0.75 & 0.992 & NS & - \\
\hline $\begin{array}{l}\text { 9. My child reacts, in my opinion, well on me when I play and talk with } \\
\text { him/her }\end{array}$ & 5.71 & 0.56 & 5.83 & 0.38 & -1.396 & NS & + \\
\hline 10. I am happy with how my child reacts when I hug him/her & 5.82 & 0.42 & 5.85 & 0.42 & -0.402 & NS & + \\
\hline Sum score Factor 1 & 55 & 4.93 & 55.3 & 3.26 & -0.368 & NS & + \\
\hline
\end{tabular}

Satisfaction Motherhood Factor 2; Support of surrounding area

11. I am pleased with the contribution my partner makes to the care of my child

12. I am satisfied with the contribution my partner makes to the household

chores

13. I feel supported by the information and advice I got from doctors, nurses or health centers about the care and development of my child

14. I have in my mind sufficient contact with other parents with small children

15. I feel supported by the help of my family, friends or acquaintances in the care of my child

16. I feel I can adequately appeal to people in my neighbour environment to baby-sit my child when necessary

17. If I have problems with my child or as I am concerned about the future, I can talk about it with my partner

\begin{tabular}{|c|c|c|c|c|c|c|}
\hline 5.3 & 1.12 & 5.35 & 0.9 & -0.296 & NS & + \\
\hline 4.88 & 1.17 & 4.9 & 1.2 & -0.115 & NS & + \\
\hline 4.88 & 1.03 & 4.73 & 1.03 & 0.812 & NS & - \\
\hline 5.25 & 0.9 & 5.17 & 1.06 & 0.442 & NS & - \\
\hline 5.08 & 1.34 & 5.17 & 1.08 & -0.42 & NS & + \\
\hline 4.92 & 1.39 & 4.79 & 1.35 & 0.536 & NS & - \\
\hline 5.58 & 0.94 & 5.8 & 0.4 & -1.81 & NS & + \\
\hline 5.26 & 1.08 & 5.71 & 0.54 & -3.113 & $<.01$ & + \\
\hline 41.3 & 5.84 & 42 & 3.53 & -0.819 & NS & + \\
\hline 96.3 & 9.07 & 97.2 & 5.66 & -0.697 & NS & + \\
\hline
\end{tabular}

18. If I have problems with my child or if I am concerned about the future, I

can talk about it with family or friends

Sum score Factor 2

Satisfaction Motherhood total score

96

\section{NOSI-K Factor 1; Fastidiousness}

21. My child does things that make me feel pretty troubled*

24. The parentage of this child is more difficult than I thought it would be*

34. There are a few things that my child does that quite bothers me*

35 My child has more demands on me than other children to their mother*

38. Caring for my child turns out to be more problematic than I expected*

42. My child seems harder to take care off than most children*

Sum score Factor 3

\section{NOSI-K Factor 2; Behavior child}

19. It is not always easy to accept my child as he/she is*

20. Lately, I find it very difficult to make decisions regarding my child*

27. My child's attention wanders off more often than I expected*

39. My child has daytime fluctuating votes*

40. If my child gets something fails he/she usually worse his/her mood more than other children*

41. Often I don't understand my child*

43. If my child is upset, he/she is usually pretty hard to calm*

Sum score Factor 4

\begin{tabular}{|c|c|c|c|c|c|c|}
\hline 5.43 & 1.18 & 5.69 & 0.65 & -1.546 & $\mathrm{NS}$ & + \\
\hline 4.99 & 1.66 & 5.29 & 1.05 & -1.279 & $\mathrm{NS}$ & + \\
\hline 5.08 & 1.46 & 5.13 & 1.17 & -0.229 & $\mathrm{NS}$ & + \\
\hline 5 & 1.7 & 5.58 & 0.89 & -2.485 & $\mathrm{p}<.05$ & + \\
\hline 5.3 & 1.36 & 5.65 & 0.81 & -1.827 & $\mathrm{NS}$ & + \\
\hline 5.14 & 1.6 & 5.62 & 0.97 & -2.068 & $\mathrm{p}<.05$ & + \\
\hline 31 & 7.64 & 33.2 & 3.48 & -2.178 & $\mathrm{p}<.05$ & + \\
\hline
\end{tabular}

\section{NOSI-K Factor 3; Competence}

23. I often feel that I can't handle so well the things I do*

25. I have much more trouble raising children than I expected*

28. How I do my best to educate my child, sometimes I feel I can't handle the situation*

29. Often, when I see other parents busy with their children, I think: "That kind of mother, I would also like to be "*

30. I often feel like to give up*

31. I look with confidence to the further education of my child

32. I feel I am not as capable of caring my child as I thought*

Sum score Factor 5

\begin{tabular}{|c|c|c|c|c|c|c|}
\hline 5.12 & 1.51 & 5.37 & 1 & -1.139 & NS & + \\
\hline 5.51 & 1.09 & 5.63 & 0.66 & -0.67 & NS & + \\
\hline 4.72 & 1.57 & 5.12 & 1.11 & -1.665 & NS & + \\
\hline 5.41 & 1.1 & 5.33 & 1.08 & 0.413 & NS & - \\
\hline 5.25 & 1.34 & 5.25 & 1.24 & 0 & NS & 0 \\
\hline 5.39 & 1.05 & 5.4 & 0.98 & -0.05 & NS & + \\
\hline 5.47 & 1.13 & 5.35 & 1.01 & 0.657 & NS & - \\
\hline 37 & 6.54 & 37.8 & 4.11 & -0.773 & NS & + \\
\hline 4.99 & 1.37 & 5.29 & 0.92 & -1.401 & NS & + \\
\hline 5.17 & 1.26 & 5.49 & 0.88 & -1.571 & NS & + \\
\hline 4.92 & 1.36 & 4.94 & 1.24 & -0.09 & NS & + \\
\hline 5.41 & 1.09 & 95.3 & 70.8 & 60.236 & NS & - \\
\hline 5.56 & 0.93 & 5.83 & 0.51 & -2.066 & NS & + \\
\hline 5.38 & 1.21 & 5.51 & 1.05 & -0.617 & NS & + \\
\hline 5.7 & 0.82 & 5.77 & 0.47 & -0.573 & NS & + \\
\hline 37.1 & 6.15 & 38.3 & 3.62 & -1.294 & NS & + \\
\hline & & & & & & + \\
\hline
\end{tabular}




\section{NOSI-K Factor 4; Fatigue}

22. By the constant activity of my child, I often feel very tired*

26. Since I have children, I am quickly tired than before*

Sum score Factor 6

\section{NOSI-K Factor 5; Difficulties child}

33. My child is often difficult and then it is difficult to have such a child*

36. If I forbid my child something, he/she does it later anyway*

37. My child often requires more attention from me than I can give*

Sum score Factor 7

\section{NOSI-K Total score}

\begin{tabular}{|c|c|c|c|c|c|c|}
\hline 3.78 & 1.66 & 4.12 & 1.48 & -1.185 & NS & + \\
\hline 2.72 & 1.56 & 2.69 & 1.57 & 0.119 & NS & - \\
\hline 6.5 & 2.9 & 6.8 & 2.47 & -0.626 & NS & + \\
\hline \multicolumn{7}{|l|}{} \\
\hline 5.36 & 1.28 & 5.33 & 1.04 & 0.132 & NS & - \\
\hline 3.42 & 1.47 & 3.76 & 1.52 & -1.274 & NS & + \\
\hline 4.83 & 1.27 & 4.73 & 1.03 & 0.463 & NS & - \\
\hline 13.6 & 3.19 & 13.8 & 2.59 & -0.407 & NS & + \\
\hline 125.2 & 22.39 & 130.5 & 12.33 & -1.682 & NS & + \\
\hline
\end{tabular}

* Items were rescored, so that a high corresponds with positive response

NS, not significant

$\mathrm{Di}$;

$$
\begin{array}{ll}
- & \text { Experimental group scored higher } \\
+ & \text { Control group scored higher } \\
0 & \text { No score difference }
\end{array}
$$

\begin{tabular}{|c|c|c|c|c|c|c|c|c|c|}
\hline & SM Doings child & $\begin{array}{l}\text { SM Support } \\
\text { surrounding }\end{array}$ & $\begin{array}{l}\text { NOSI Fasti- } \\
\text { diousness }\end{array}$ & $\begin{array}{l}\text { NOSI Behavior } \\
\text { child }\end{array}$ & $\begin{array}{l}\text { NOSI } \\
\text { Competence }\end{array}$ & NOSI Fatigue & \begin{tabular}{|l|} 
NOSI \\
Difficulties child
\end{tabular} & Total SM & Total NOSI \\
\hline SM Doings child & 1.00 & & & & & & & & \\
\hline $\begin{array}{l}\text { SM Support of } \\
\text { surrounding }\end{array}$ & $0.40^{* *}$ & 1.00 & & & & & & & \\
\hline $\begin{array}{l}\text { NOSI Fasti- } \\
\text { diousness }\end{array}$ & $0.74 * *$ & $0.37 * *$ & 1.00 & & & & & & \\
\hline $\begin{array}{l}\text { NOSI Behavior } \\
\text { child }\end{array}$ & $0.61 * *$ & $0.41^{* *}$ & $0.69^{* *}$ & 1.00 & & & & & \\
\hline $\begin{array}{l}\text { NOSI } \\
\text { Competence }\end{array}$ & $0.45 * *$ & $0.46^{* *}$ & $0.59 * *$ & $0.74 * *$ & 1.00 & & & & \\
\hline NOSI Fatigue & $0.48^{* *}$ & $0.26^{*}$ & $0.52 * *$ & $0.54 * *$ & $0.55 * *$ & 1.00 & & & \\
\hline $\begin{array}{l}\text { NOSI Difficulties } \\
\text { child }\end{array}$ & $0.42 * *$ & $0.24^{*}$ & $0.54^{* *}$ & $0.59^{* *}$ & $0.62 * *$ & $0.46^{* *}$ & 1.00 & & \\
\hline Total SM & $0.81 * *$ & $0.87 * *$ & $0.64 * *$ & $0.59 * *$ & $0.54 * *$ & $0.43 * *$ & $0.38 * *$ & 1.00 & \\
\hline Total NOSI & $0.69 * *$ & $0.45^{* *}$ & $0.86^{* *}$ & $0.90 * *$ & $0.86^{* *}$ & $0.69 * *$ & $0.75^{* *}$ & $0.66 * *$ & 1.00 \\
\hline
\end{tabular}

Table 2. Results of correlation analysis of patient group ( $\mathrm{SM}=$ Satisfaction Motherhood subscale, NOSI $=$ NOSI-K subscale).

* Correlation is significant at the 0.05 level

\begin{tabular}{|c|c|c|c|c|c|c|c|c|c|}
\hline & SM Doings child & $\begin{array}{l}\text { SM Support } \\
\text { surrounding }\end{array}$ & $\begin{array}{l}\text { NOSI Fasti- } \\
\text { diousness }\end{array}$ & $\begin{array}{l}\text { NOSI Behavior } \\
\text { child }\end{array}$ & $\begin{array}{l}\text { NOSI } \\
\text { Competence }\end{array}$ & NOSI Fatigue & \begin{tabular}{|l|} 
NOSI \\
Difficulties child
\end{tabular} & Total SM & Total NOSI \\
\hline SM Doings child & 1.00 & & & & & & & & \\
\hline $\begin{array}{l}\text { SM Support of } \\
\text { surrounding }\end{array}$ & $0.38^{* *}$ & 1.00 & & & & & & & \\
\hline $\begin{array}{l}\text { NOSI Fasti- } \\
\text { diousness }\end{array}$ & 0.24 & $0.37 * *$ & 1.00 & & & & & & \\
\hline $\begin{array}{l}\text { NOSI Behavior } \\
\text { child }\end{array}$ & $0.34^{*}$ & $0.44 * *$ & $0.70^{* *}$ & 1.00 & & & & & \\
\hline $\begin{array}{l}\text { NOSI } \\
\text { Competence }\end{array}$ & 0.26 & $0.47 * *$ & $0.58 * *$ & $0.70^{* *}$ & 1.00 & & & & \\
\hline NOSI Fatigue & 0.11 & 0.07 & $0.28^{*}$ & 0.26 & 0.22 & 1.00 & & & \\
\hline $\begin{array}{l}\text { NOSI Difficulties } \\
\text { child }\end{array}$ & 0.24 & $0.37 * *$ & $0.53 * *$ & $0.61 * *$ & $0.43^{* *}$ & $0.43^{* *}$ & 1.00 & & \\
\hline Total SM & $0.82 * *$ & $0.85^{* *}$ & $0.37^{*}$ & $0.47 * *$ & $0.45^{* *}$ & 0.09 & $0.37 * *$ & 1.00 & \\
\hline Total NOSI & $0.29 *$ & $0.45^{* *}$ & $0.83 * *$ & $0.90 * *$ & $0.80 * *$ & $0.53 * *$ & $0.75^{* *}$ & $0.44 * *$ & 1.00 \\
\hline
\end{tabular}

** Correlation is significant at the 0.01 level

Table 3. Results of correlation analysis of day-care group $(\mathrm{SM}=$ Satisfaction Motherhood subscale, NOSI $=$ NOSI-K subscale $)$.

* Correlation is significant at the 0.05 level

** Correlation is significant at the 0.01 level

Secondly, we need to mention the low response rate in the child day care group (20.8\%) versus the patient group $(61.8 \%)$. This is possibly due to a positive selection bias. Perhaps the mothers in the child day care group who participated were ones that were satisfied with motherhood. However, in that case a difference between the patient and the child day care groups would have been obvious.

Another limitation is that access to cleft patients for research was bounded to the cleft team of the Academic Centre of Dentistry Amsterdam, which lowers the external validity. Therefore, it is difficult to generalize the findings of this study. Results might be different for patients treated by other cleft teams. In the current study, the sample size is relatively small, making it impossible to examine differences within the patient group. Also, the effect size of differences found between the two groups is relatively small. In a future study, more cleft teams should be involved, increasing the sample size and making the effect size more interesting.

One more limitation of the present study is that only mothers participated. In a future study, fathers should also be included. 
Table 4. Results from the stepwise regression analyses for the experimental and the control groups.

\begin{tabular}{|c|c|c|c|c|}
\hline \multirow[b]{2}{*}{ Subscales } & \multicolumn{2}{|c|}{ Experimental group } & \multicolumn{2}{|c|}{ Control group } \\
\hline & $\underline{\beta}$ & p & $\underline{\beta}$ & $\underline{p}$ \\
\hline Doings child & 0.2 & 0.08 & -0.02 & 0.91 \\
\hline Support & 0 & 0.99 & 0.25 & 0.1 \\
\hline Fastidiousness & 0.18 & 0.13 & -0.13 & 0.51 \\
\hline Behavior child & 0.15 & 0.28 & 0.47 & $.00^{*}$ \\
\hline Competence & 0.53 & $.00 *$ & 0.23 & 0.23 \\
\hline Fatigue & 0.08 & 0.52 & 0.2 & 0.15 \\
\hline Difficulties child & $\underline{0.03}$ & $\underline{0.85}$ & $\underline{0.21}$ & $\underline{0.21}$ \\
\hline
\end{tabular}

${ }^{*} \mathrm{p}<.01$

Table 5. Explorative questions; item mean scores (M), standard deviations (SD).

\begin{tabular}{|l|l|l|}
\hline Explorative questions & Cleft \\
\hline $\begin{array}{l}\text { I feel I have enough contact with other parents with a child with } \\
\text { a cleft }\end{array}$ & 3.67 & 1.91 \\
\hline $\begin{array}{l}\text { I feel I enjoy the first weeks after birth as much as mothers } \\
\text { without children with a cleft }\end{array}$ & 3.84 & 1.99 \\
\hline $\begin{array}{l}\text { I feel supported by information and advice I got from the cleft } \\
\text { team about the care and development of my child }\end{array}$ & 5.12 & 1.02 \\
\hline $\begin{array}{l}\text { I am reluctant to visit doctors, nurses practitioners, health centers } \\
\text { or the cleft team with my child }\end{array}$ & 5.13 & 1.40 \\
\hline
\end{tabular}

Stress experienced by parents affects the development of a child; therefore, stress should be considered and minimized. The cleft team might check whether mothers actually experience stress and are satisfied about motherhood. If it appears that a mother is experiencing stress or is less satisfied with motherhood, the cleft team could help by ensuring that the mother's sense of competence about raising their child increases. For example, providing parenting courses, focusing on the child with an orofacial cleft; handling daily routines, coping with reactions from other people, learning to be resilient, and/or providing relaxation exercises. In a future study, the effect of these interventions should be studied. Mothers of children with clefts felt less able to talk with family or friends about a problem with their child. Therefore, the cleft team might bring the existence of peer associations and support groups to the attention of the parents.

\section{Acknowledgements}

The authors thank the parents who participated in this study. We want to acknowledge the contribution of Kirsten Graven who was responsible for the data collection.

\section{Conflicts of interest}

The authors declare that they have no conflict of interest.

\section{Author contributions}

$\mathrm{AB}$ coordinated the study, $\mathrm{CP}$ commented on the manuscript throughout the writing process, PS contributed during the semi-final and final stages of the manuscript.

\section{References}

1. Endriga MC, Kapp-Simon KA (1999) Psychological issues in craniofacial care: state of the art. Cleft Palate Craniofac J 36: 3-11. [Crossref]

2. Klein T, Pope AW, Getahun E, Thompson J (2006) Mothers' reflections on raising a child with a craniofacial anomaly. Cleft Palate Craniofac J 43: 590-597. [Crossref]

3. Pelchat D, Bisson J, Ricard N, Perreault M, Bouchard JM (1999) Longitudinal effects of an early family intervention programme on the adaptation of parents of children with a disability. Int Journal Nurs Stud 36: 465-477. [Crossref]
4. Andrews-Casal M, Johnston D, Fletcher J, Mulliken JB, Stal S, Hecht JT (1998) Cleft lip with or without cleft palate: Effect of family history on reproductive planning, surgical timing, and parental stress. Cleft Palate Craniofac J 35: 52-57. [Crossref]

5. Bradbury ET, Hewison J (1994) Early parental adjustment to visible congenital disfigurement. Child Care Health Dev 20: 251-266. [Crossref]

6. Kramer FJ, Baethge C, Sinikovic B, Schliephake H (2007) An analysis of quality of life in 130 families having small children with cleft lip/palate using the impact on family scale. Int J Oral Maxillofac Surg 36: 1146-1152. [Crossref]

7. Prahl C, Prahl-Andersen B, Van't Hof MA, Kuijpers-Jagtman AM (2008) Presurgical orthopedics and satisfaction in motherhood: A randomized clinical trial (Dutchcleft). Cleft Palate Craniofac J 45: 284-288. [Crossref]

8. Benson BA, Gross AM, Messer SC, Kellum G, Passmore LA (1991) Social support networks among families of children with craniofacial anomalies. Health Psychol 10: 252-258. [Crossref]

9. Endriga MC, Speltz ML (1997) Face-to-face interaction between infants with orofacial clefts and their mothers. J Pediatr Psychol 22: 439-453. [Crossref]

10. Grollemund B, Guedeney A, Vazquez MP, Picard A, Soupre V, et al. (2012) Relationa development in children with cleft lip and palate: influence of the waiting period prior to the first surgical intervention and parental psychological perceptions of the abnormality. BMC Pediatr 12: 65. [Crossref]

11. Johansson B, Ringsberg KC (2004) Parents' experiences of having a child with cleft lip and palate. $J$ Adv Nurs 47: 165-173. [Crossref]

12. Murray L, Hentges F, Hill J, Karpf J, Mistry B (2008) Cleft lip and palate study team. The effect of cleft lip and palate, and the timing of lip repair on mother-infant interactions and infant development. J Child Psychol Psychiatry 49: 115-123. [Crossref]

13. Speltz ML, Armsden GC, Clarren SS (1990) Effects of craniofacial birth defects on maternal functioning postinfancy. J Pediatr Psychol 15: 177-196. [Crossref]

14. Kandel I, Merrick J (2003) The birth of a child with disability. Coping by parents and siblings. Scientific World Journal 3: 741-750. [Crossref]

15. Maris CL, Endriga MC, Speltz ML, Jones K, DeKlyen M (2000) Are infants with orofacial clefts at risk for insecure mother-child attachments? Cleft Palate Craniofac J 37: 257-265. [Crossref]

16. Pope AW (1999) Points of risk and opportunity for parents of children with craniofacial conditions. Cleft Palate Craniofac J 36: 36-39. [Crossref]

17. Bos A, Prahl C (2011) Oral health-related quality of life in Dutch children with cleft lip and/or palate. Angle Orthod 81: 865-871. [Crossref]

18. Lei RL, Wang SL, Cheng CP, Chen PK, Chin CC (2010) Psychometric evaluation of the stress scale for parents with cleft lip and/or palate children (SSPCC) - A preliminary study. Cleft Palate Craniofac Journal 47: 482-490.

19. Nelson P, Glenny AM, Kirk S, Caress AL (2012) Parents' experiences of caring for a child with a cleft lip and/or palate: a review of the literature. Child Care Health Dev 38: 6-20. [Crossref]

20. Krueckeberg SM, Kapp-Simon KA (1993) Effect of parental factors on social skills of preschool children with craniofacial anomalies. Cleft Palate Craniofac J 30: 490-496. [Crossref]

21. Pelchat D, Ricard N, Bouchard JM, Perreault M, Saucier JF, et al. (1999) Adaptation of parents in relation to their 6-month-old infant's type of disability. Child Care Health Dev 25: 377-397. [Crossref]

22. Pope AW, Tillman K, Snyder HT (2005) Parenting stress in infancy and psychosocial adjustment in toddlerhood: A longitudinal study of children with craniofacial anomalies. Cleft Palate Craniofac J 42: 556-559.

23. Lazarus RS, Folkman S (1984) Stress, appraisal and coping. Springer, New York, USA

24. Goldberg S, Janus M, Washington J, Simmons RJ, MacLusky I, Fowler RS (1997) Prediction of preschool behavioral problems in healthy and pediatric samples. $J$ Dev Behav Pediatr 18: 304-313. [Crossref]

25. Shaw WC, Semb G, Nelson P, Brattström V, Mølsted K (2001) The Eurocleft project 1996-2000: overview. J Craniomaxillofac Surg 29: 131-140. [Crossref]

26. Hoeksma JB, Koomen HMY, Koops W (1987) Responsiviteit en hechting; een enquête bij ouders van kinderen met en kinderen zonder een schisis [Responsiveness and adhesion, a survey of parents of children with and children without a cleft]. Nederlands Tijdschrift voor de Psychologie 42: 282-291. 
27. Hoeksma JB, Koomen HMY (1991) Development of early mother-child interaction and attachment. Amsterdam Vrije Universiteit Dissertation.

28. Abidin RR (1983) Parenting stress index manual. Pediatric Psychology Press, Charlottesville, VA, USA.

29. Brock de AJLL, Vermulst AA, Gerris JRM (1990) De Nijmeegse Ouderlijke Stress Index [The Nijmegen Parenting Stress Index]. Gezin, Tijdschrift voor primaire leefvormen 2: 1-18.
30. Brock de AJLL, Vermulst AA, Gerris JRM, Abidin RR (1992) NOSI Nijmeegse Ouderlijke Stress Index. Meetinstrument voor de vaststelling van stress bij opvoeders. Een uitgebreide versie (NOSI) voor psychodiagnostische doeleinden en een verkorte versie (NOSIK) voor signaleringsdoeleinden [NOSI Nijmeegse Ouderlijke Stress Index. An instrument to measure parental stress. An extensive version (NOSI) for diagnostic purposes and an abbreviated version (NOSIK) for screening purposes] Swetz \& Zeitlinger, Lisse.

Copyright: $(02017$ Bos A. This is an open-access article distributed under the terms of the Creative Commons Attribution License, which permits unrestricted use, distribution, and reproduction in any medium, provided the original author and source are credited. 